\title{
THE EVOLUTION OF TRANSPORT NETWORKS
}

\author{
David Levinson \\ Department of Civil Engineering \\ University of Minnesota \\ 500 Pillsbury Drive SE \\ Minneapolis, MN 55455 USA \\ levin031@tc.umn.edu
}

\section{DRAFT - FOR REVIEW ONLY}

\section{INTRODUCTION}

Between 1900 and 2000, the length of paved roads in the United States increased from $240 \mathrm{~km}$ to $6,400,000 \mathrm{~km}$ (Peat 2002, BTS 2002) with virtually $100 \%$ of the U.S. population having almost immediate access to paved roadways. Similarly, in 1830 there were $37 \mathrm{~km}$ of railroad in the United States, but by 1920 total track mileage had increased more than ten-thousand times to $416,000 \mathrm{~km}$ miles, however since then, rail track mileage has shrunk to about 272,000 km (Garrison 1996, BTS 2002). The growth (and decline) of transport networks obviously affects the social and economic activities that a region can support; yet the dynamics of how such growth occurs is one of the least understood areas in transport, geography, and regional science. This is revealed time and again in the long-range planning efforts of metropolitan planning organizations (MPOs), where transport network changes are treated exclusively as the result of top-down decision-making. Changes to the transport network are rather the result of numerous small decisions (and some large ones) by property owners, firms, developers, towns, cities, counties, state department of transport districts, MPOs, and states in response to market conditions and policy initiatives. Understanding how markets and policies translate into facilities on the ground is essential for scientific understanding and improving forecasting, planning, policymaking, and evaluation.

Charles Darwin laid out the idea we refer to as evolution, survival of the fittest, or natural selection in his Origin of Species. He constructed natural selection in analogy with the artificial selection that animal breeders use to create new varieties. The idea that species randomly change over time, and the fitter variations are more likely to survive and propagate than the less fit variations has now become commonplace. Darwinian evolution has been used as a metaphor in statistical analysis (the genetic algorithm) (Holland 1975), artificial intelligence (Minsky 1986) and in brain development (neural Darwinism) (Edelman 1987). In particular the logic of brain development seems particularly relevant, as the neural connections in the brain (the neural network) are analogous to other networks such as transport. The neural Darwinism argument suggests that at birth there are many connections in the brain, some of which are more useful than others. More useful connections are reinforced, while less useful connections are deprecated. These approaches contrast with creationist arguments, that species (along with their ecological niches) were designed, or that we are born hard-wired, that are nolonger favored in the biological community.

Without becoming theological, it is clear that the idea that planning, engineering, and the intentions of decisionmakers drives the topology of networks is a top-down creationist viewpoint, in contrast with a model which suggests that networks evolve, with successful facilities being expanded, and less successful transport sections 
allowed to whither. This chapter of the Handbook considers the theory and evidence surrounding network evolution models. The aim of network evolution models are to describe reality rather than optimality; there is no obligation to maximize welfare directly. This is in contrast to the long line of research on the Network Design Problem (Abdulaal and LeBlanc 1979, Davis 1994, Friesz 1985, Friesz et al. 1998, Huang and Bell 1999, Sanderson 2001). However, the deviation of actual decisions from welfare maximizing decisions are worth noting.

The evolutionary perspective considers how species come to be, how ecological niches are filled. Using this metaphor, one could think of links as being the equivalent of species, and the links they are connected to being higher or lower on the food chain (traffic being consumed in a predator-prey relationship). Alternatively, we can consider the network as an individual organism that develops over time. An analogy for that circumstance is to what extent "nature" or the genetic programming drives development of an organism (measured in various ways: physical structure, intelligence, personality, language, etc.), in contrast with "nurture" or the influence of relatives (especially parents), friends, and peers, as well as the availability of resources (food, clean air and water, education, etc.) on that same development. If we apply the nature vs. nurture argument to networks, the question is to what extent simple rules (the rules by which travelers choose to use certain links over others, the rules by which resources for network expansion are obtained, the rules which give us the cost of network expansion, and the rules by which investments are made) drive development in contrast with decisions being made for political or other circumstances determining where the network will be expanded and contracted.

As with the nature vs. nurture argument in human development, this may be a false dichotomy. It is clear that without the genetic programming, intelligence would be impossible. But without resources, education, and care, intelligence would also be impossible. At best we can assess the marginal contribution of each to something that doesn't vary too much across the general population.

This chapter consider macroscopic and microscopic perspectives on network evolution in turn. The macroscopic perspective examines S-curves and changes in investment patterns over time. The microscopic perspective problematizes node formation, link formation, and link expansion and reviews each. The chapter concludes with some notes about future research and applications.

\section{A Macroscopic Perspective}

The macroscopic perspective on network evolution has been examined in a great deal of research, especially at the Institute for Applied Systems Analyses (IASA) in Austria (Garrison 1987, 1989; Nakicenovic 1988, 1989; Marchetti 1988; Batten 1989; Grübler 1990). What has been most noted is the emergence of "S-curves", which relate time to deploy a network (or any technology) with market saturation. For a period of time (the growth phase), as knowledge of a technology (a mode) and realization of its benefits spreads, the rate of adoption increases. In the phrasing of a once overplayed Faberge hair products commercial "I'll tell two friends, and they'll tell two friends, and so on, and so on." Each project acts as a demonstration to potential new users. Furthermore, the advantages to adoption may increase with the number of users if there are network or interfirm scale, scope, or sequence economies. As the technology diffuses, those who expect to attain the most benefit adopt it first. After a point, diminishing marginal returns set in. (That is, once more than half the people know, many of the friends they tell already have the product or have decided against it). It is expected that, after complete exposure, technology is adopted by those who gain the most, and then by those who gain less and less from it, until it is fully deployed. 
Diminishing marginal returns limits growth, but there is also the issue of decline. Canals, for instance, were made obsolete by railroads, illustrating that the life of a technology may be cut short by competition. Alternatively, as in the case of plank roads, a technology may collapse because a technological problem is discovered shortly after deployment (wooden planks deteriorated much sooner than expected). Figure 1 illustrates S-curves for a number of transport technologies in the United States.

One would expect S-shaped curves, because transport is a product like others, it enters and floods a market. Observation suggests that it takes 60 to 70 years for a transport system to run its growth cycle from launch to saturation in the first major market. (However, in places where the technology is adopted later, growth occurs faster because the course is well trodden and learning can be cut-short by simpler copying).

To aid in understanding the behavior of a system as it runs its S-curve, the life-cycle metaphor may help. Broadly there are three main phases: birth, growth, and maturity. There may be subsequent phases of decline and death, as the S-curve runs backwards (perhaps it should be called a Z-curve). The period of birth is one of possibility, many new technologies and networks are conceived, yet few are realized. There is an explosion of possible evolutionary paths, yet only one is taken. To illustrate, consider automobile technologies. At the onset of the twentieth century, the form of the auto was unclear. Loosely, it would be similar in size to horse and carriage, but would it be powered by steam, electricity, gasoline, or otherwise? Would it serve business travel or leisure travel predominantly (it started as a toy for weekend trips, but later took on a more serious role)? For various reasons, a particular technical path is selected, and ultimately locked-in; in the case of the auto that path was the gasoline powered engine. The more gasoline engines that have been purchased, the more valuable it is for new autos to have gasoline engines, since the gasoline distribution network is already in place. These network externalities are established by the point of transition from birth to growth. The growth phase sees process improvements and technological honing; economies of scale and scope take hold, and costs drop while benefits increase. In the third phase, the network has saturated its market niche, and the focus switches from deployment to management, from growth to maintenance. Because the system is mature, there little additional to be gained (by the existing system) from technological advances, advances will rock the boat and move the status quo, with which most players are comfortable. Of course change does eventually occur, but it is often the "next new thing" rather than a modification of the network in place.

Systems seem to face diminishing investment in new technology as a system moves through its life cycle. It would be only rational to make the most cost-effective improvements in a process first, and then the next best thing and so on. While previous improvement may open new opportunities, it is likely that each improvement is slightly less effective than the previous, at least after some point. For instance, the fan jet engines used by jet aircraft are approaching the limits on the thrust that can be obtained from them; the Otto cycle engine is just about as fuel efficient as it can be made to be. Batten and Johannsson (1985) observed that investment in product development is high during early days of the life cycle, but that as time passes, more-and-more attention is paid to processes of production.

The relationship to these S-curves for dominant technologies and the economy as a whole has not gone unnoticed. Researchers have associated "long-waves" in the economy of prosperity, recession, and depression (Kondratieff cycles), with waves of innovation, often waves of transport and communication technologies. Mensch (1979) argues for waves of innovations that trigger investment and jobs, but as those technologies begin to age there is recession and then depression. Recovery begins as another wave of innovations begins. Yet this 
process leaves open the question of what causes waves of innovation. Garrison and Souylerette (1996) present the Companion-Innovation hypothesis, which says that opportunities created when transport (and communication) systems are innovated and deployed trigger waves of innovations. In other words, transport (and communication) systems create new opportunities in other economic sectors, allowing people not only to do the same things better (faster, cheaper), but to do new things that were previously inconceivable. Those innovations drive further changes.

A line of research examines how transport investment affects the economy at large, but tends to treat transport (or highways) as a black box, and makes no distinctions between different kinds of transport investment (Aschauer 1989, Gramlich 1994, Nadiri 1996, Boarnet 1997, Button 1998). The input is investment in transport (or infrastructure), and output is gross domestic product, typically measured at the state level. The research has shown that in the United States investment in transport has been declining, and that the effectiveness of transport investments (the rate of return) has also been declining over the last 40 years of the twentieth century. Those observations are consistent with transport (particularly highways) being in a mature stage. Just as transport investment affects the economy, the economy affects investment patterns. Carruthers and Ulfarsson (2001) find that various public service expenditures like roadways are influenced by demographic and political characteristics. The New Jersey Office of State Planning (1996) also finds a similar pattern in roadways expenditure.

Miyao (1981) developed macroscopic models to take transport improvements as either an endogenous effect of urban economy or as an exogenous effect on the economy. Endogenous growth theory suggests that economic growth is a two-way interaction between the economy and technology; technological research transforms the economy that finances it (Aghion and Howitt 1998). The Companion-Innovation hypothesis of Garrison argues that transport is not only unlikely to be an exception, but may be the most important transformation agent in the economy: through revenue sources like the gas tax, transport investment drives the growth that funds it.

The life-cycle model can be represented by the following equation

$$
\frac{f}{1-f}=e^{a t+b}
$$

Where:

$f=$ fractional share of technology (technology's share of final market share)

$t=$ time

$a, b=$ model parameters

Such a tool may help in forecasting, because if the final size of the market can be assessed, and some deployment has already taken place, the pace of future growth can be understood broadly. On the other hand, this cannot tell what the microscopic decisions are that will situate a network in space, or will indicate small upturns and downturns. Further, for many technologies, the final size of the market is unclear until after the fact. For instance, how large will the internet be? Figure 2 below suggests an alternative (the best fit on the available data using equation 1 suggests a maximum of some 600,000,000 internet host computers), though that number may be obviated by the time this handbook is in print. 
Macroscopic models allow us to identify a general process for describing how technologies are deployed. But they do not really help us understand the underlying individual decisions on deployment, except to the extent that networks are deployed faster (in percentage terms) the younger they are.

\section{Microscopic Models}

Few researchers have considered the process of transport network growth at the microscopic level, highlighting the importance of this research. Taaffe et al. (1963) study the economic, political and social forces behind infrastructure expansion in underdeveloped countries, finding that initial roads are developed to connect regions of economic activity and lateral roads are built around these initial roads. A positive feedback between infrastructure supply and population was also observed. Barker and Robbins (1975) investigated the London Underground's growth, but did not develop a theoretical framework.

The network evolution question at the microscopic level divides itself into several related problems. The first considers the location of network nodes. The second considers the connection of nodes with links. The third considers the sizing of links and the hierarchy of roads.

\section{The Node Location Problem}

The location of network nodes reminds us of the geographer's central place question (Christaller 1933, 1966). Christaller's Central Place Theory (CPT) arose in response to the question of how urban settlements are spaced, more specifically, what rules determine the size, number and distribution of towns. The question of network evolution is in many respects similar, but we may think of it as the question of what rules determine the size, number, and distribution of links (or nodes). Christaller's model made a number of idealizing assumptions, especially regarding the ubiquity of transport services, in essence, assuming the network problem away. His world was a largely undifferentiated plain (purchasing power was spread equally in all directions), with central places (market towns) that served local needs. The plain was demarcated with a series of hexagons (which approximated circles without gaps or overlaps), the center of which would be a central place. However some central places were more important than others because those central places had more activities. Some activities (goods and services) would be located nearer consumers, and have small market areas (for example a convenience store) others would have larger market areas to achieve economies of scale (such as warehouses).

Table 1: Important US nodes: Largest Metropolitan Areas

\begin{tabular}{ll}
\hline City & Feature in dominant city \\
\hline New York-Northern New Jersey-Long & harbor \\
Island, NY-NJ-CT-PA & \\
Los Angeles-Riverside-Orange County, & harbor \\
CA & \\
Chicago-Gary-Kenosha, IL-IN-WI & harbor, river/canal connections to Mississippi \\
Washington-Baltimore, DC-MD-VA- & harbor (Baltimore), capital (Washington) \\
WV & \\
San Francisco-Oakland-San Jose, CA & harbor \\
Philadelphia-Wilmington-Atlantic City, & harbor \\
PA-NJ-DE-MD & \\
Boston-Worcester-Lawrence, MA-NH- & harbor \\
\hline
\end{tabular}


ME-CT

Detroit-Ann Arbor-Flint, MI

Dallas-Fort Worth, TX

Houston-Galveston-Brazoria, TX

Atlanta, GA

Miami-Fort Lauderdale, FL

Seattle-Tacoma-Bremerton, WA

Cleveland-Akron, $\mathrm{OH}$

Minneapolis-St. Paul, MN-WI

Phoenix-Mesa, AZ

San Diego, CA

St. Louis, MO-IL

Pittsburgh, PA

Denver-Boulder-Greeley, CO strategic crossing

trading post/crossing of Trinity River

harbor

rail terminus

rail terminus, resort

harbor

river/canal terminus, Great Lakes port

St. Anthony Falls on Mississippi River, most northerly navigable location

site of an ancient Native American irrigation system, Salt River

harbor

confluence of Missouri and Mississippi rivers

confluence of Allegheny and Monongahela rivers with Ohio river

gold discovery at the confluence of Cherry Creek and the South Platte River (resource extraction)

The preceding paragraph does not do justice to Christaller, but his research has been extended by geographers and regional scientists (Losch 1938, Heilbrun 1987). Models developed by Batty and Longley (1985), Landis (1994), Krugman (1996), and Waddell (2001) all use newer modeling ideas, treating the problem in a decentralized fashion, and consider land use dynamics, allowing central places to emerge. However, those models, too, take the network as given.

In a more empirical sense, observation suggests that nodes emerge for a variety of reasons. Nodes occur at points of resource extraction (e.g. a mining town). Nodes occur at points of energy extraction (a waterfall) where a natural energy source can be exploited. Nodes also occur at points of trans-shipment, where nature's links (rivers and oceans) can be exploited. Nodes may also be located for military advantage (to protect an area against incursion by other forces). These nodes may then be connected with each other by links. Links may then cross, creating new nodes with high levels of accessibility. Table 1 shows the twenty largest U.S. cities and their principal natural feature that was exploited.

If this argument is believed, it was in a sense inevitable that there would be nodes at these places. However, what may not have been inevitable was the size of the node, that is, there are a number of places which may have had equivalent natural bounty, but never became a top 20 city. However investigation of the history of these cities suggests that transport was the dominant reason for their existence, be it the movement of goods, energy, or water for irrigation. In most cases waterways acted as conduits of travel, in several (Detroit, Dallas), the waterway was largely a barrier that was narrowest at these points compared with others, and in Phoenix, it was the water that was the resource. That said, it further argues that it is geographical asymmetries that drive the growth of nodes (a node has some advantage over all places that were not selected as nodes).

\section{The Link Formation Problem}

The construction of new links can be modeled in several ways. In the first set of considerations, we assume we know the location of nodes. We could assume that all (or a very large number of) nodes are connected, but at 
some very low speed, and then use a network expansion model (such as discussed below) to reinforce selected links and allow others to whither, much as neurons develop in the brain of an infant (Edelman 1987) or a neural network model learns. In contrast with this Darwinian selection process, we could assume that, for every node, there is a set of possible nodes it can connect with (neighbors within a certain radius that it does not already connect with directly). Constraints about crossing existing links could be established. We could incorporate forecasts or expected demand were the link to be built. Then a choice model, based on accessibility added or expected volume served based on the traffic of existing links using that node, would select new links to be added. In this vein, Garrison and Marble (1965) observed connections to the nearest large neighbor explained the sequence of rail network growth in Ireland.

Alternatively, we could specify a process for simultaneous link formation and generation of new nodes. It is reasonable that nodes are generated by one of three processes: the location of natural features (e.g harbors and waterfalls), the location of artificial features (e.g. the intersection of two roads connecting different places), or explicit design (the nodes shall be in a grid spaced every 1 mile). The first two are most interesting for exploring network evolution. A more general process then can be formulated: First each step adds a node (networks are assembled one node at a time). Second attach each node to two other nodes with two links. The rules for attachment then become critical. As Barabasi et al. (1999) note, if nodes were more likely to connect with already well-connected nodes, we would have a scale-free network (resembling airline hubbing). But if nodes connected randomly to neighbors, we would have a random network that more resembles highways. Scale-free networks follow a power rule in the distribution of node-connectedness. However while the connection structure of highways is limited to nodes being connected to usually at most 4 others, the links that connect them have attributes that differentiate them. Just as hubs are hierarchically organized in node-based system, some links are more important in the hierarchy than others: they are faster, wider, and carry more traffic. Yamins et al. (2003) develop a simulation that grows urban roads using simple connectivity rules proportional to the activity at locations.

To some extent both the Darwinian and the choice process reflect aspects of the growth of real networks. The Darwinian process is probably best suited to undeveloped areas being opened, with access provided and cost of construction being the main offsetting factors. In particular we can think of the Darwinian process being appropriate in areas without developed transport planning, where animal trails are adopted by humans on foot, and later roads are built over those trails. The choice process better reflects the more 'sophisticated' process of building a new link in already developed areas (or areas adjacent to developed areas). Even rural areas that already have a road network can be considered developed from this perspective.

\section{The Link Expansion (Contraction) Problem}

When a transport facility is built or expanded, travel increases on that facility both due to re-routing and rescheduling and due to what is often called induced or latent demand, a finding confirmed at both the macroscopic level (states and counties) (Noland 1998, Strathman et al. 2000, Fulton et al. 2000) and at the microscopic level (individual links) (Parthasarathi et al. 2002). As travel costs for commuters are lowered, the number of trips and their length increase. In market sectors of the economy, as population grows and preferences shift, leading to higher demand, suppliers produce more of a good. While surface transport decisions are often made in the political arena rather than the market, politicians and officials also respond to their customers - the voter and taxpayer. Although over the short-run transport supply is relatively inelastic; in the long-run it varies. However, it is not known to what extent changes in travel demand, population, income, 
and demography drive these long-run changes in supply. Answering this induced supply question in transport is a critical step in understanding the long-term evolution of transport networks.

Observation suggests the hypothesis that decisions to expand transport networks are largely myopic in both time and space, usually ignoring non-immediate and non-local effects. This myopic decision process, when applied sequentially, tends to improve the relative speeds and capacities of links that are already the most widely used, and thereby expand their use. The rate and extent of this process is constrained by the cost of those improvements and limited budgets. The full ramification of network expansion on future infrastructure decisions is seldom considered. Improving one link will cause complementary (upstream and downstream) links to have greater demand, and competitors (parallel links) to have lesser demand (and be less likely to be improved). These network effects both complicate the problem and may suggest a structure for analysis.

In particular, the phenomenon of network hierarchy is an important issue. For instance, roads are classified in a way that designates most roads as relatively low speed, low volume links. Only a few links on the hierarchy of roads carry the bulk of traffic. Although planners and engineers design for the hierarchy of roads, those designs are constrained by previous decisions. In many respects, the hierarchy of roads is the network analogue of geography's central place theory, which seeks to explain how hierarchies of places develop (Christaller 1966).

Yerra and Levinson (2003) simulate the link expansion problem, showing how a network can differentiate into a hierarchical network from either a random or a uniform network. The network, like observed networks, exhibits power-rule type of behavior, a few very fast links, some moderate speed links, and many slower links. They observe that the hierarchical structure of a network emerges as a function of induced demand (travelers take advantage of additional capacity by making longer trips as well as rerouting), cost functions with certain economies of scale, revenue proportionate to demand, an investment rule that embeds a "rich get richer" (but not "winner take all") logic, reflecting that important links get reinforced, and an underlying network structure (grid, radial etc.). This model contained no comprehensive master plan applied to a tabula rasa. In brief, the hierarchy of roads would exist even if no planners or engineers intended it.

We can think of each link as an agent that chooses its speed based on preferences and constraints. There are several exogenous inputs: the base network, the distribution of land uses and demographics, and user specified events. There is also a travel demand model that translates land use data into traffic flows and speeds on network links. Those traffic flows and speeds inform the network investment model. Those flows also determine the revenue and costs of maintaining and improving the link. When each link has exhausted its resources, the time period is incremented, population grows, land uses are updated, the travel demand is recomputed on the new network, and the process repeats.

Figure 3 shows the evolution of link speeds on 2 stylized grid networks using the above formulation. The thickness (and color) of the line indicates the speed of the link divided into 4 categories with the widest bars being fastest. As can be seen, the network with an initial uniform distribution of link speeds develops into a hierarchical network with some faster links attracting more traffic and slower links serving local land uses and less traffic. Clearly the degree to which the network differentiates depends on particular model parameters. The 10x10 grid with an even number of streets in the north-south and the east-west direction maintains symmetry with two major North-South and East-West streets. (A 15x15 grid, with an odd number of streets in the northsouth and east-west direction, and thus an equal number of streets to both the left and right of the center street, has only one). Though the network is symmetric, it has boundaries, and it is those boundary conditions (the 
links at the edge serve traffic differently than links in the interior as traffic at the edge tends to go inward) that allow differentiation to occur even with a uniform land use and equally spaced links of identical initial speed. The economies of scale (additional flow increases costs less than linearly) along with increasing costs for higher speed links drive the system to the equilibrium where link costs equal link revenue. The second case, showing a random initial distribution of link speeds, illustrates a more complex hierarchical emergence, one that is not symmetric. It is one where initial conditions strongly determine final results. Research shows that other types of initial differences (for instance a higher density downtown, natural topographical features, or random events or random distribution of other initial conditions) further differentiate the system.

Karamalaputi and Levinson (2003a) empirically estimate choice models of highway network expansion and new construction. The network expansion model aims to predict which links will be expanded based on empirical factors (anticipated cost, length, traffic flow on the link, a parallel link, and upstream and downstream links, year, budget constraint, type of road, and population of neighboring areas). Those variables were generally important in prediction. Levinson and Karamalaputi's (2002) empirical prediction of new construction is by its very nature more difficult, since the choice set is not limited to existing links, but rather to all potential links. Determining the set of plausible highway links requires developing rules (maximum length of link, connections to existing nodes, etc.) that make prediction feasible. Still this is a harder problem and will require significant further study.

\section{CONCLUSIONS}

The physical network as an object of study is a relatively new endeavor, which complements studies of land use, traffic flows, and social networks (Watts 1999). The development of network evolution models at the macroscopic and microscopic perspectives offers new insights into processes that previously were thought to result from the visible hand of planners, engineers, and politicians. While there is of course a residual to the analysis that can be explained as the product of conscientious decision-makers, there is a large part of network growth that is driven by the underlying geography, economy, and technology. Both the estimation of individual component models and their integration into a simulation of network growth (and decline) will increase our heretofore-limited understanding of network evolution processes. This new understanding will have broad impacts on transport planning practice, and ultimately on the shape of cities and regions. In particular, it will provide a tool to illustrate the implications of current decisions on the future shape of the network, a consideration that is lacking in most planning and engineering studies. By providing a glimpse into a suggested future network configuration, cognizant policy can aim to redirect investment to produce an alternative set of preferred future investments.

Incorporating explicit measures of network externalities in decision-making will lead to better plans, network routing decisions, and implementation strategies. Understanding and illustrating how decisions at one point of time affect future choices should help guide planners and decision-makers desiring to shape the future. The long-term consequences of incremental changes will be assessed. This will help decision-makers assess the effects of changed policies, expanding existing facilities or routes, or building in new rights-of-way or offering new services. This improved understanding of long-term network dynamics would lead to better planning and design of road networks to exploit network externalities and maximize future choice for decision makers. 
It is worth speculating about the implications of network evolution on the future of transportation technology. Transportation and telecommunications serve as both complements and substitutes. The capacity of telecommunications networks to provide 'virtual' presence in contrast to the 'physical' presence provided by the transportation network may affect the long term demand for, thus provision of, new transportation networks. Figure 2 illustrated the potential growth of the internet, which is but one of many emerging communications networks. The increasing use of communications networks undoubtedly changes individual daily activity patterns as it has already changed business. Whether we will see a pattern of the expansion of communications resulting in a diminished investment in transportation (much as steamboats replaced sail or the airplane replaced intercity rail), or an expansion (the telegraph enabling the long distance railroad) remains to be seen, but merits continued monitoring.

One of the key applications of communications technology in the transportation domain has been in the intelligent transportation systems arena, which have absorbed a great deal of research effort over the past two decades. While many of the investments are responses to maturity (traveler information to slightly improve the quality of a trip, or ramp meters to slightly improve capacity), the long term goal is in the direction of vehicles which can drive themselves. This may be seen as an effort to give birth to a new mode rather than an incrementalist response to an existing mode.

\section{REFERENCES}

Abdulaal, M. and L. LeBlanc (1979) Continuous Equilibrium Network Design Models. Transportation Research 13B 19-32

Aghion, P. and P. Howitt, (1998) Endogenous Growth Theory Cambridge MA, MIT Press..

Aschauer, D (1989) Is Public Expenditure Productive? Journal of Monetary Economics Mar. 1989a 23(2) 177200.

Barabasi, A., R. Albert, and H. Jeong (1999) Scale-free characteristics of random networks: the topology of the world wide web, Physica A 272 173-187. 34

Barker, T.C. and M. Robbins (1975) A History of London Transport, Volume 1 and 2. Allen and Unwin, London Batty, M. and P. Longley (1985) The Fractal Simulation Of Urban Structure Cardiff, Wales : Department of Town Planning, University of Wales Institute of Science and Technology, Papers in planning research; 92.

Boarnet, M. (1997) Infrastructure Services and the Productivity of Public Capital: The Case of Streets and Highways, National Tax Journal, 50(1), pp. 39-57, March, 1997

Button, K. (1998) Infrastructure investment, endogenous growth and economic convergence Annals of Regional Science 32 (1), pp. 145-162

Christaller, W. (1966) Central Places in Southern Germany. Englewood Cliffs, New Jersey Prentice Hall (Translated by Carlisle W. Baskin).

Edelman, G. (1987) Neural Darwinism. Basic Books, New York, New York.

Friesz, T. (1985) Transportation Network Equilibrium, Design and Aggregation: Key Development and Research Opportunities . Transportation Research, 19A 413-427

Friesz, T.L., S. Shah, and D. Bernstein (1998): Disequilibrium Network Design: A New Paradigm for Transportation Planning and Control . Network Infrastructure and the Urban Environment, Springer, pp.99-111. 
Fulton, L.M., R.B., Noland, D.J. Meszler and J.V. Thomas (2000): A Statistical Analysis of the Induced Travel Effects in the U.S. Mid-Atlantic Region. Journal of Transportation and Statistics, vol.3, no.1, pp.1-14.

Garrison, W. L. (1996) CE250 Course Notes University of California at Berkeley mimeo.

Garrison, W.L., and Marble, D.F. (1965). "A prolegomenon to the forecasting of transportation development." Office of Technical Services, United States Department of Commerce, United States Army Aviation Material Labs Technical Report.

Garrison, W. L. and R. R. Souleyrette (1996) "Transportation, Innovation, and Development: The Companion Innovation Hypothesis," Logistics and Transportation Review, 32: 5-37

Garrison, W. L. (2000) Innovation and Transportation's Technologies Journal of Advanced Transportation 32:1 31-63

Gramlich E. (1994) Infrastructure Investment: A Review Essay, Journal of Economic Literature 32 pp. $1176-$ 1196.

Grübler, A. (1990) The Rise and Fall of Infrastructures : Dynamics of Evolution and Technological Change in Transport. Heidelberg: Physica-Verlag.

Heilbrun, J. (1987) Urban Economics and Public Policy, 3rd Edition. New York: St. Martin's Press

Holland J.H. (1975), Adaptation in natural and artificial system, Ann Arbor, The University of Michigan Press,. Holland, J. (1995) Hidden Order: How Adaptation Builds Complexity Reading, Mass. : Addison-Wesley.

Huang, H.J. and Bell, M. (1999) Continuous Equilibrium Network Design Problem with Elastic Demand: Derivative Free Solution Methods. Transportation Networks: Recent Methodological Advances. Selected Proceedings of the $4^{\text {th }}$ Euro Transportation Meeting 175-193.

Karamalaputi, R. and D. Levinson (2003). Induced Supply: A Microscopic Analysis of Network Growth accepted for publication Journal of Transport Economics and Policy

Krugman, P. R. (1996) The Self-Organizing Economy. Cambridge, Mass. : Blackwell Publishers.

Landis, J. (1994) The California Urban Futures Model : A New Generation Of Metropolitan Simulation Models. Environment and planning B: planning and design, Vol. 21 pp. 399-420.

Levinson, D. (2002) Financing Transportation Networks Northampton Mass., Edward Elgar Publishers.

Levinson, D. and R. Karamalaputi (2002). Predicting New Highway Construction: A Comparison of Logit, Probit, and Mixed Logit Models working paper

Lösch, A. (1938) "The Nature of Economic Regions," Southern Economic Journal, Vol. 5, No. 1, July pp. 71-78 Mensch, G. (1979) Stalemate in Technology Ballinger, Cambridge, Massachusetts.

Minsky, Marvin. (1986) The Society of Mind. New York: Simon and Schuster.

Miyagi, T. (1998) A Spatial Computable General Equilibrium Approach for Measuring Multiregional Impacts of Large Scale Transportation Projects. Network Infrastructure and the Urban Environment, Springer, pp.224-244.

Miyao, T. (1981) Dynamic Analysis of the Urban Economy. Academic Press, New York.

Nadiri, M. Ishaq and T. Mamuneas (1996) Contribution of Highway Capital to Industry and National Productivity Growth. Federal Highway Administration.

New Jersey Office of State Planning (1996) Projecting Municipal Road Costs under Various Growth Scenarios. Document \# 109.

Noland, R. B (1999) Relationships Between Highway Capacity and Induced Vehicle Travel. Transportation Research Board $78^{\text {th }}$ Annual Meeting Preprint CD-ROM, Transportation Research Board, National Research Council, Washington DC, January 1999.

Parthasarathi, P., D. Levinson, R. Karamalaputi (2002) Induced Demand: A Microscopic Perspective. Accepted for publication Urban Studies. 
Peat, F.D. (2002) From Certainty to Uncertainty: The Story of Science and Ideas in the Twentieth Century. National Academy Press: Washington DC p. xiii

Sanderson, K. (2001) Building Our Way Out of Congestion? A Network Design Problem for the Twin Cities. M.S. Thesis. Dept of Civil Engineering University of Minnesota.

Strathman, J.G., K.J. Dueker, T. Sanchez, J. Zhang, and A.E. Riis (2000): Analysis of Induced Travel in the 1995 NPTS . Center for Urban Studies, Portland State University, Portland.

Taaffe, E.J., R.L. Morrill, and P.R. Gould (1963): Transport Expansion in Underdeveloped Countries . Geographical Review 53, pp.503-529.

Wadell, P. (2001) UrbanSim: Modeling Urban Development for Land Use, Transportation, and Environmental Planing. Paper Presented to the $17^{\text {th }}$ Pacific Conference of the Regional Science Association, June 30 July 4, 2001

Watts, D. (1999) Small Worlds Princeton, NJ Princeton University Press

Yamins, D., S. Rasmussen, D. Fogel (2003) Growing Urban Roads Networks and Spatial Economics, 3:(2003) 69-85.

Yerra, B. and D. Levinson (2002) The Emergence of Hierarchy in Transportation Networks under review Annals of Regional Science. 
Levinson, David (2005) The Evolution of Transport Networks,

Chapter 11 ( pp 175-188) in Handbook 6: Transport Strategy, Policy and Institutions (David Hensher, ed.) Elsevier, Oxford

Proportion of Maximum Extent

Networks as a Proportion of Maximum Extent

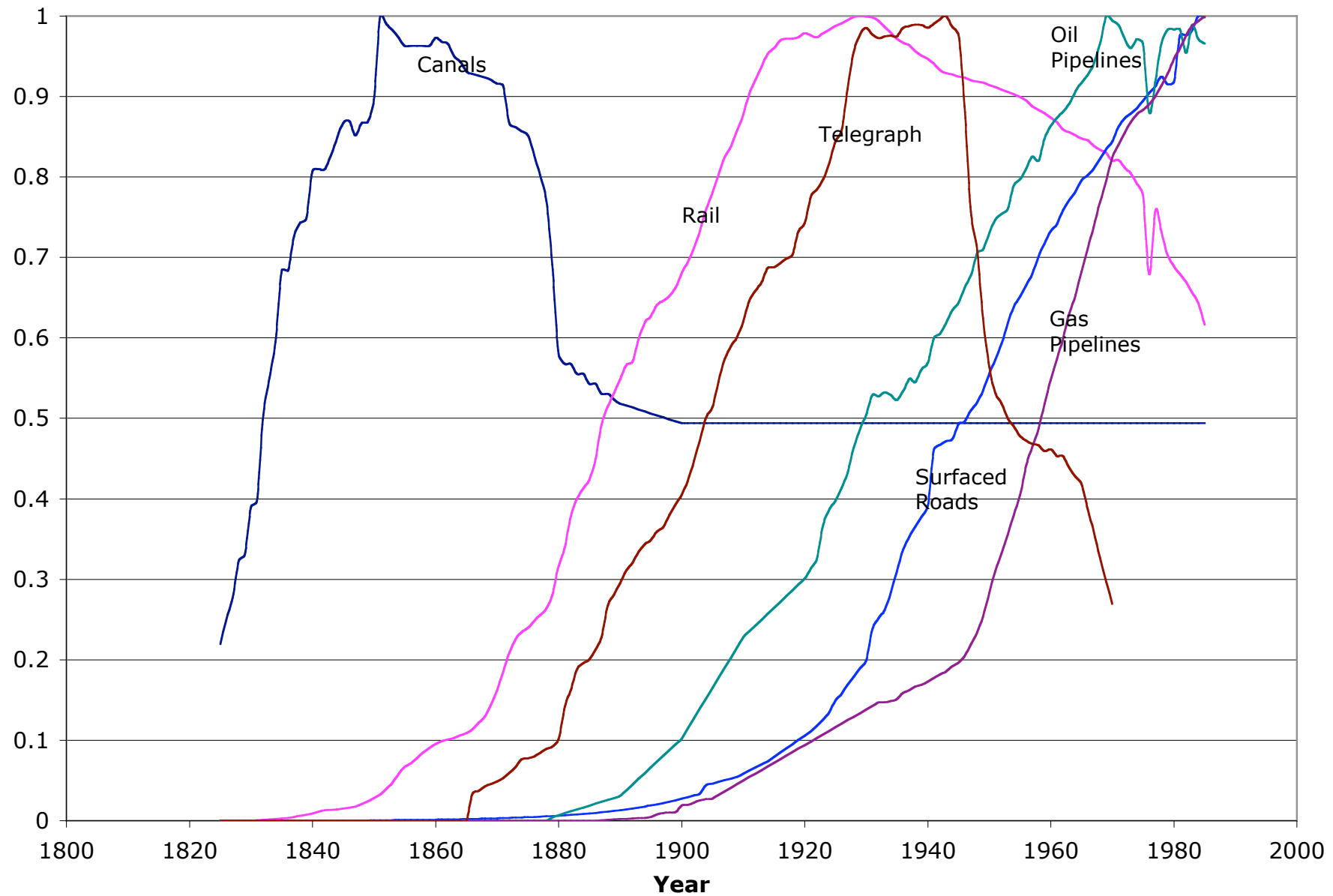

Figure 7.1 U.S. Networks as a Proportion of Maximum Extent 
Levinson, David (2005) The Evolution of Transport Networks,

Chapter 11 ( pp 175-188) in Handbook 6: Transport Strategy, Policy and Institutions (David Hensher, ed.) Elsevier, Oxford

Figure 2: Internet Host Computers, Observed, Extrapolated

\section{Internet Host Computers}

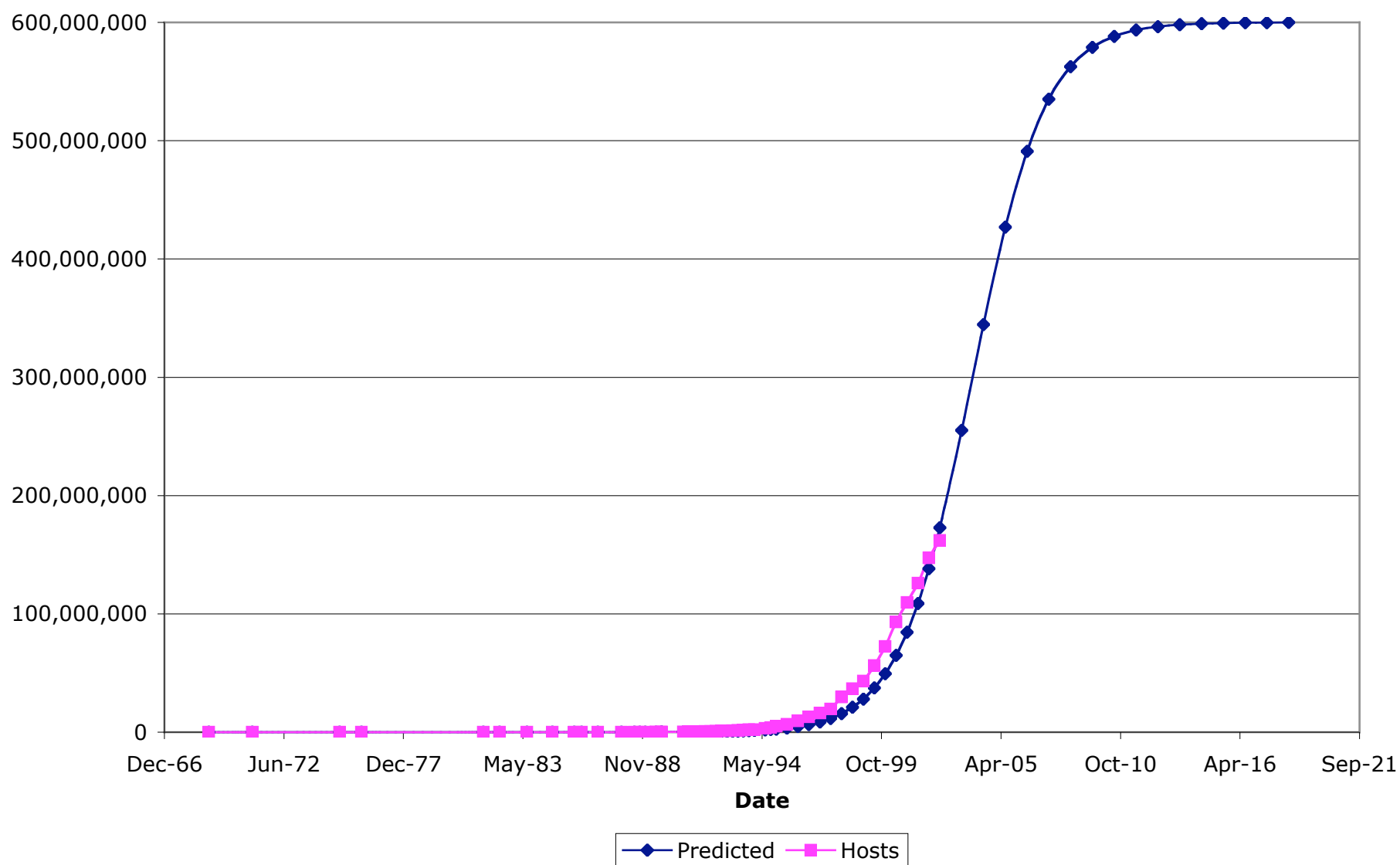


Case 1: 10 x 10 Grid, Uniform Initial Speed = 1, Uniform Land Use
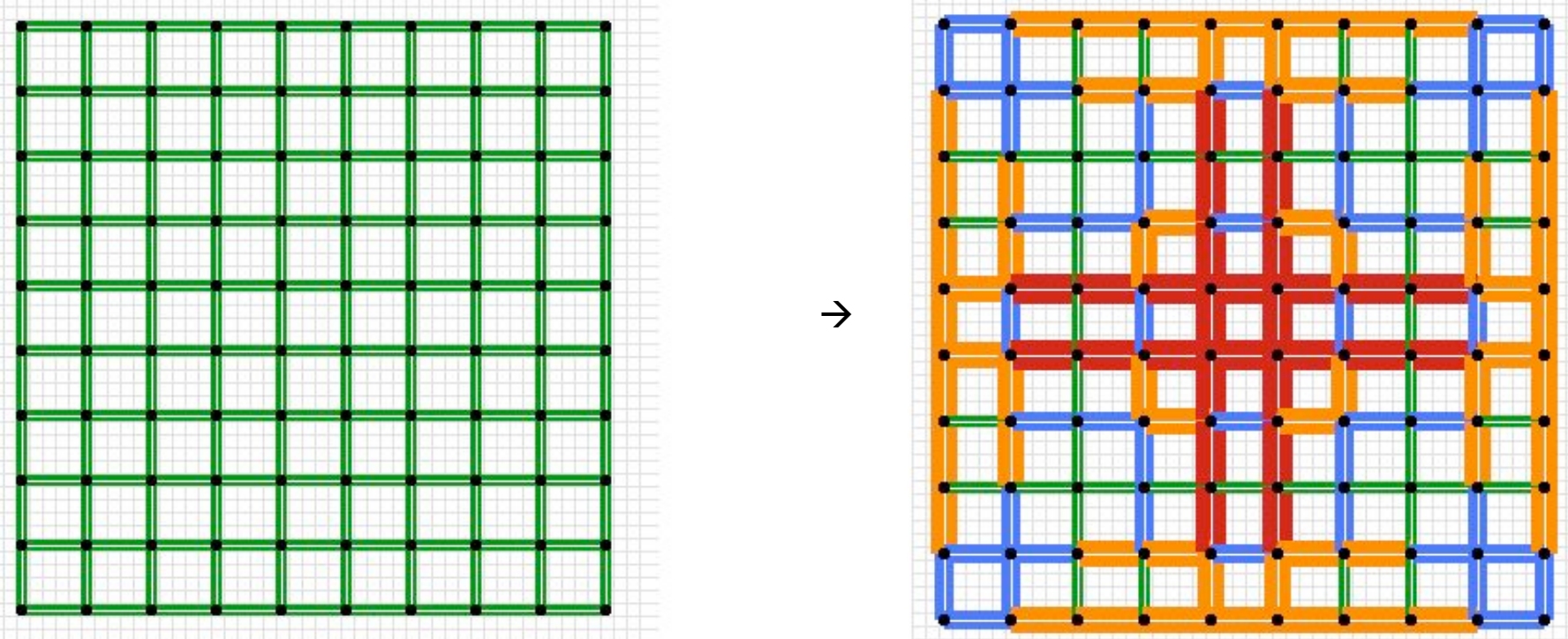

Case 2: 10 x 10 Grid, Random Initial Speed (Distributed between 1 and 5), Uniform Land Use
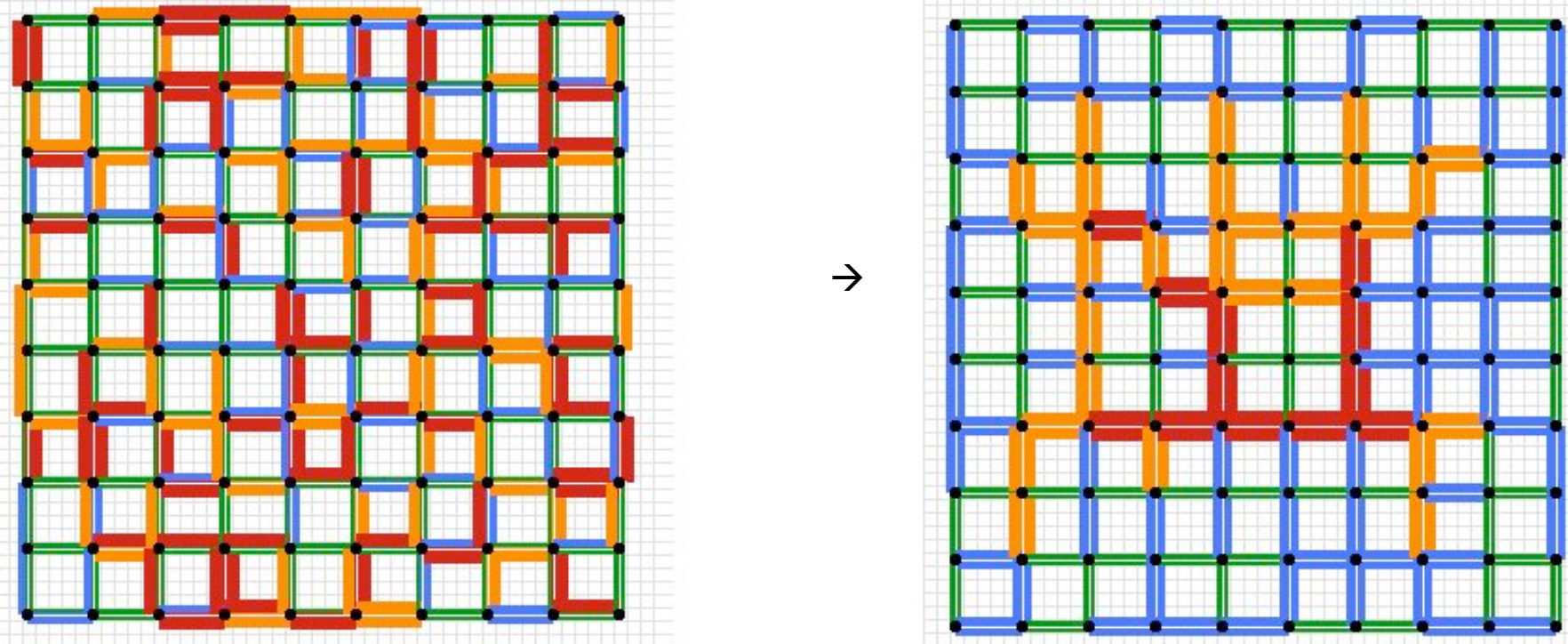

Figure 3: Link Expansion: the Evolution of an abstract grid network (Yerra and Levinson 2002) 